\title{
Cold-induced vasoconstriction for preventing onycholysis during cancer treatment
}

\author{
Lola Bladt ${ }^{1}$, Jonathan De Clercq ${ }^{1}$, Tom Janssens ${ }^{1}$, Johan Van Hulle ${ }^{1}$, Jochen Vleugels ${ }^{1}$, Jean-Marie Aerts², \\ Guido De Bruyne ${ }^{1 *}$
}

From 15th International Conference on Environmental Ergonomics (ICEE XV)

Portsmouth, UK. 28 June - 3 July 2015

\section{Introduction}

Chemotherapy induced nail toxicity is observed in up to $88 \%$ of cancer patients. Onycholysis, a severe form of nail toxicity in which the nail is detached from the nail bed, is observed in $0 \%$ to $44 \%$ of cancer patients undergoing a taxanes based chemotherapy. The use of ice gloves may reduce incidence rates for chemotherapy induced onycholysis, but cause cold and pain. In this research it was hypothesized that the use of local active cooling would reduce blood flow in the distal phalanxes, whilst inducing less discomfort as compared to an ice glove.

\section{Methods}

Twelve healthy test persons, six male and six female, participated in this study. Average age was 22 years. Three test cases were induced (independent variables): active cooling of the right hand at $2{ }^{\circ} \mathrm{C}$, active cooling of the right hand at $10{ }^{\circ} \mathrm{C}$ and passive cooling of the right hand with an ice glove cooled at $-18^{\circ} \mathrm{C}$ prior to the test, resulting in 36 experiments. Active cooling controlled local skin temperature on the dorsal side of the proximal phalanges with the use of peltier elements. Local blood flow at the distal phalanges was assessed with the use of laser Doppler optometry (moorVMSLDF2) under the nailbed and with the use of skin temperature $\left({ }^{\circ} \mathrm{C}\right)$ measurements on the palmar side of the phalanges (dependent variable). Cooling effectiveness (\%) was quantified as the relative change in the area under the curve of blood flow for distal phalanges I to $\mathrm{V}$ during the 30 minutes cooling period compared to a baseline that was measured for five minutes prior to the

\footnotetext{
* Correspondence: guido.debruyne@uantwerpen.be

'Product Development, Faculty of Design Sciences, University of Antwerp, Belgium

Full list of author information is available at the end of the article
}

experiment. Ambient air temperature was $20^{\circ} \mathrm{C}$ (SE $\left.0.4^{\circ}\right)$. Thermal comfort was evaluated with the use of a likert scale.

\section{Results}

This research showed that local active cooling of $2{ }^{\circ} \mathrm{C}$ is more effective $(85.8 \%, \mathrm{p}<0.05)$ compared to $10{ }^{\circ} \mathrm{C}$ $(91.5 \%)$ to induce vasoconstriction when blood flow is quantified through skin temperature. Blood flow assessed through laser Doppler optometry showed too large variations for providing conclusive results with respect to the effectiveness of passive cooling. Thermal comfort was significantly higher $(\mathrm{p}<0.05)$ for local active cooling as compared to passive cooling.

\section{Discussion and conclusion}

Local active cooling induces vasoconstriction at the distal phalanges of a hand and induces less discomfort as compared to an ice glove. More research is needed for providing insight in the underlying mechanisms of cold induced vasoconstriction and cold induced vasodilation to restrict blood flow under the nail bed and its effects on nail toxicity and onycholysis when taxanes are used during chemotherapy.

\section{Authors' details \\ ${ }^{1}$ Product Development, Faculty of Design Sciences, University of Antwerp, Belgium. ${ }^{2}$ M3-BIORES, Faculty of Bioscience Engineering, KU Leuven, Belgium.}

Published: 14 September 2015

doi:10.1186/2046-7648-4-S1-A60

Cite this article as: Bladt et al:: Cold-induced vasoconstriction for preventing onycholysis during cancer treatment. Extreme Physiology \& Medicine 2015 4(Suppl 1):A60. 